\title{
PRASOPHYLLUM AND ITS ASSOCIATED MYCORRHIZAL FUNGI
}

\author{
Emily McQualter ${ }^{1,2,3,4}$, Rob Cross $^{2}$, Cassandra B. McLean ${ }^{1} \&$ Pauline Y. Ladiges $^{3}$ \\ ${ }^{1}$ School of Resource Management, Burnley Campus, The University of Melbourne, \\ 500 Yarra Boulevard Richmond, Victoria, Australia, 3121 \\ ${ }^{2}$ Royal Botanic Gardens Melbourne, Birdwood Avenue, South Yarra, Victoria, Australia, 3141 \\ ${ }^{3}$ School of Botany, The University of Melbourne, Parkville, Victoria, Australia, 3052. \\ 4Author for correspondence: e.mcqualter@pgrad.unimelb.edu.au
}

KEY WORDS: mycorrhizal fungi, isolation, Prasophyllum, protocorm development, Ceratobasidium

In Victoria, there are over 330 taxa of orchid and at least half of those are threatened. The potential extinction of many of these orchids is largely due to habitat destruction caused by degradation from agriculture, industrial development and urbanisation. Effective conservation ultimately depends on the reintroduction to field sites to reinforce depleted populations. For terrestrial orchids, seed germination is the preferred method of propagation as it allows genetic variability to be maintained (Batty et al. 2006).

\section{The Genus Prasophyllum}

The genus Prasophyllum currently consists of approximately 80 recognised species in Australia and 4 species in New Zealand (Jones, 1998). Within Australia, there are two centres of diversity for the genus, southwestern Australia with 25 species ( 23 endemic) and southeastern Australia with 50 species. Within southeastern Australia, 30 species occur in Victoria. Most Prasophyllum species are threatened and restricted in distribution and overall, it is one of the most poorly known native orchid genera. (Bishop 1996).

Prasophyllum species are obligate mycotrophic plants and current conservation protocols for terrestrial orchids in Australia require propagation with symbiotic mycorrhizal fungi. Unfortunately, there is a paucity of knowledge regarding the mycosymbionts in this genus, hampering conservation and re-introduction efforts. Therefore, before recovery plans can be implemented for Prasophyllum, basic biological information is required about the nature of the mycorrhizal relationship.

This study used two threatened Prasophyllum species endemic to Victoria: Prasophyllum sp. aff. validum (Figure 1. A) and Prasophyllum diversiflorum (Gorae Leek-orchid) (Figure 2. A \& B), both from southwestern Victoria. $P$. sp. aff. validum grows in a low open grassy heathland and $P$. diversiflorum grows in open areas along watercourses and around swamp margins in heavy black loams that are inundated seasonally (Backhouse \& Jeanes 1995). First discovered in 1941 at Gorae West near Portland, the type location was lost to agriculture in 1948 , destroying all known plants. The species was rediscovered in the summer of 1983/84 (Backhouse \& Jeanes 1995) at a roadside-river crossing, and in the adjacent paddock, where several hundred plants were identified. It is known from six isolated populations in southwest Victoria, four of the six populations contain up to 200 plants while the other sites contain fewer than 20 plants.

\section{Removal of plants}

Due to the vulnerable and endangered status of $P$. sp. aff. validum and $P$. diversiflorum, respectively, collections were restricted to 16 plants of each species, four from each growth period.

A 50 meter north-south transect was set out at the Deep Lead cemetery where $P$. sp. aff validum had been observed during the previous flowering season. Sixty-nine plants of $P$. sp. aff. validum were tagged with metal pins each securing one or more swivel tags engraved with an identity mark $10 \mathrm{~cm}$ east of the growing plants. Plants were only included if they still had the previous years flowering stalks attached, so as to confirm the species identification. The numbers and location of plants were recorded for future monitoring. As the Hotspurs population has been moni- 


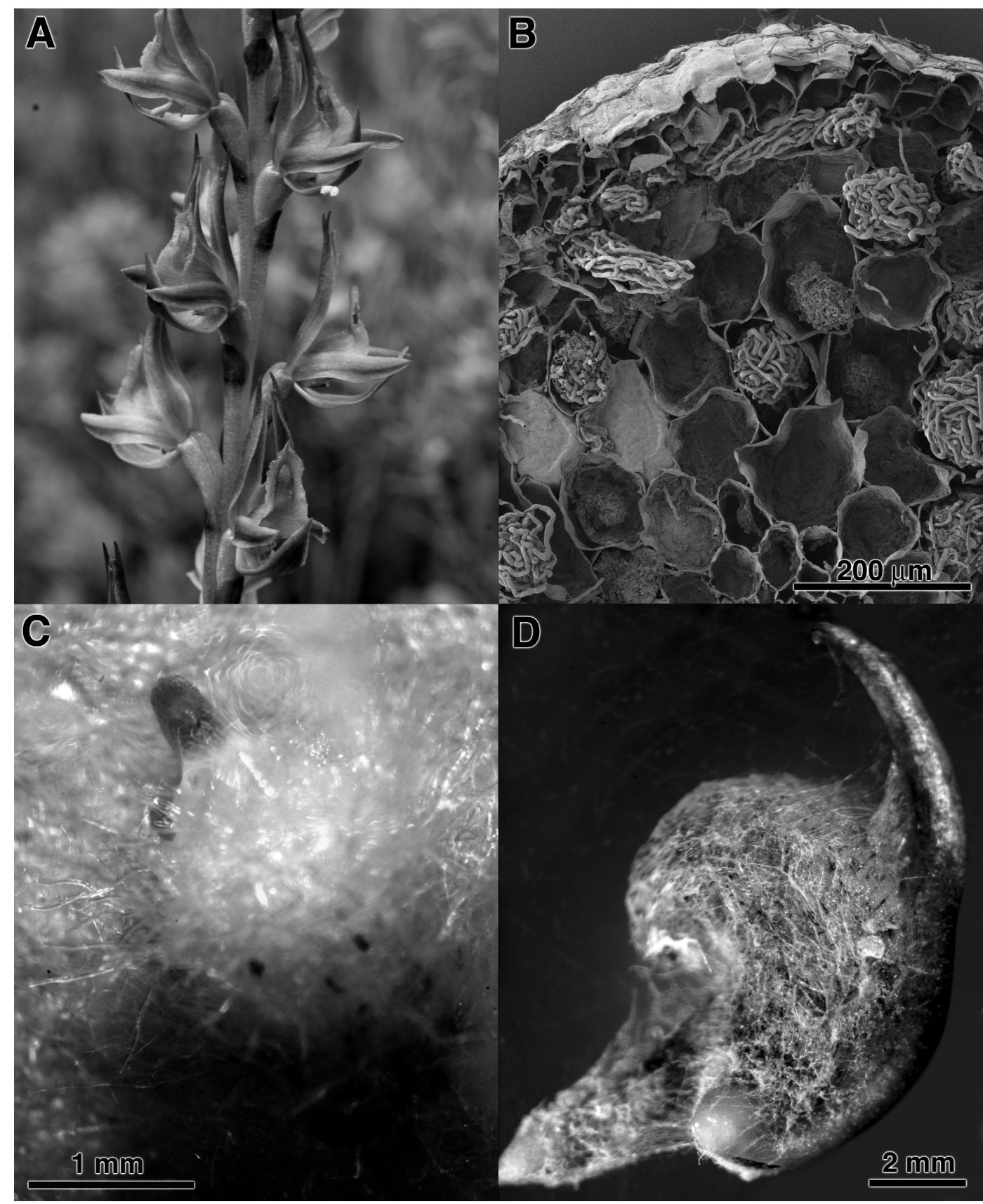

Figure 1. Prasophyllum sp. aff. validum. A. Habit. Photo: DSE. B. Peletons visible in the root section of $P$. sp. aff. validum. Photo: E. McQualter. C. Early protocorm development. Photo: E. McQualter. D. Developing seedling. Photo: E. McQualter.

tored for a number of years by the Department of Sustainability and Environment (DSE), tagging was not required of $P$. diversiflorum.

Each plant was removed as follows: a $10 \mathrm{~cm}$ circle was indented with a hand shovel around each plant and dug to a depth of $10-15 \mathrm{~cm}$. The entire plug containing above and below ground regions was carefully lifted and placed into a zip-lock bag with surrounding 


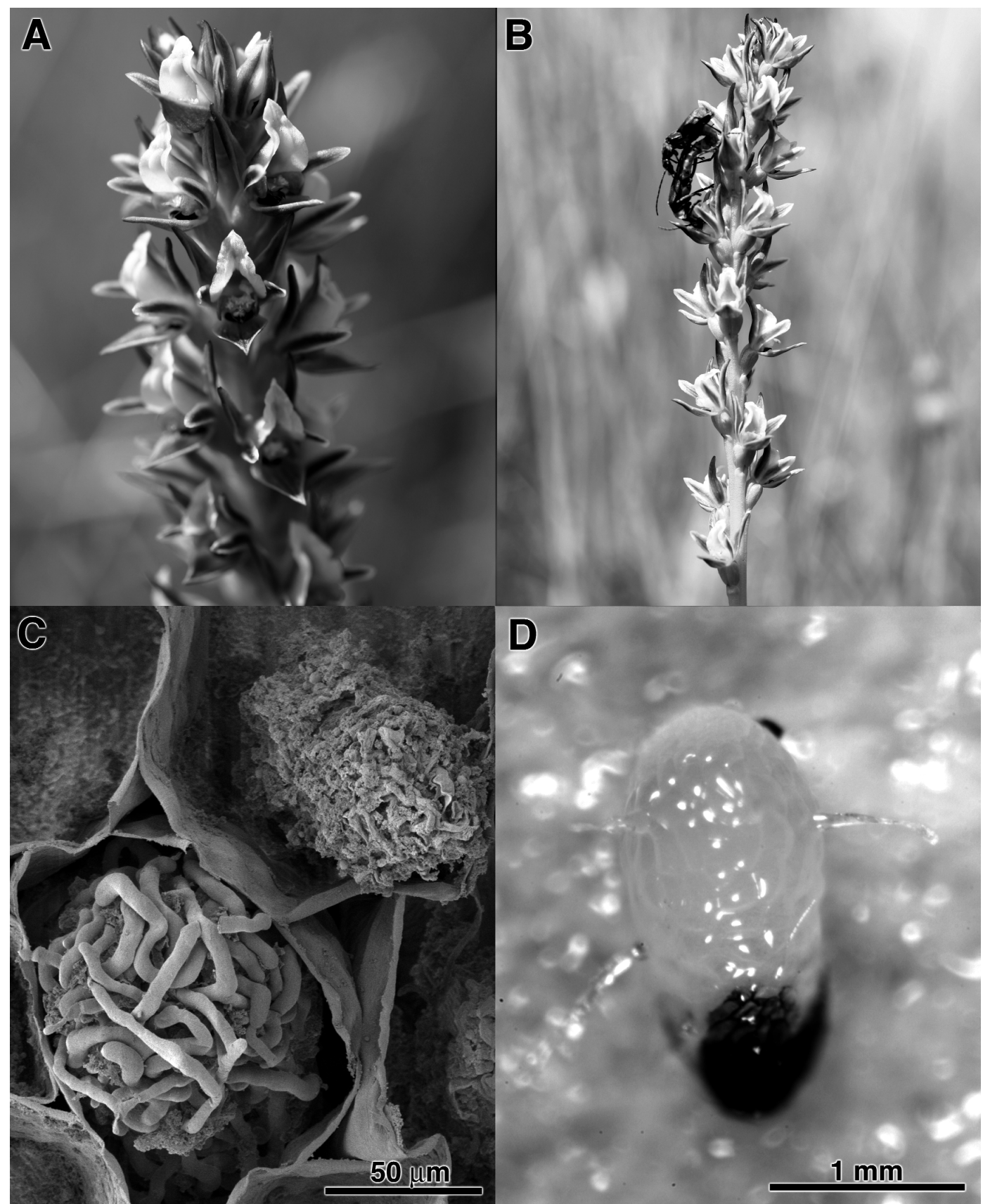

FIgure 2. Prasophyllum diversiflorum. A. Habit. Photo: DSE. B. Habit with pollinating insect. Photo: DSE. C. Healthy (lower left) and digested (upper right) peletons in a root section of $P$. diversiflorum. Photo: E. McQualter. D. Seed swelling with rhizoid formation. Photo: E. McQualter.

soil and transported to the laboratory within $24 \mathrm{hrs}$.

Plants were removed from zip-lock bags and the underground sections cleaned in running tap water until all soil was removed, the plant was then rinsed in deionised water for ten minutes. Two of the plants were cut transversely into 8 regions (Root tips, Root, Root connection, Tuber, Stem, Bottom leaf, Mid Leaf and Top leaf), then cut into sections each $2 \mathrm{~mm}$ thick. 
Each section was further cut into $1 \mathrm{~mm}$ thick longitudinal and transverse sections for light and scanning electron microscopy. The remaining plants were cut into 8 regions as before and prepared for fungal isolation. The soils plugs that remained were kept in the refrigerator at $4^{\circ} \mathrm{C}$ for ex situ seed baiting trials.

\section{Preparation for Microscopy}

Cut sections were prepared for scanning electron microscopy (SEM) and Light Microscopy (LM) by fixing and rinsing with $2.5 \%$ glutaraldehyde and $\mathrm{O} .1$ M Phosphate buffer at $\mathrm{pH} 7.4$ for two hours (modified from Beyrle et al. 1995). Sections were then washed in $0.2 \mathrm{M}$ Phosphate buffer at $\mathrm{pH} 7.4$ for 10 minutes repeated three times. Sections were then postfixed with $2 \%$ osmium tetroxide (OsO4) and 0.2 $\mathrm{M}$ Phosphate buffer at $\mathrm{pH} 7.4$ for 2 hours and rinsed in 0.2 M Phosphate Buffer three times for 20 minutes each time. The samples were then dehydrated in an ethanol series $(10,20,30,50,70,90,100 \%)$ for 15 minute, at each concentration with three additional changes in dry ethanol.

\section{Scanning Electron Microscopy}

Underground plant parts were collected for mycorrhizal isolation and SEM studies. Mycorrhizal fungi were to be isolated from adult plants at four times during 2006: soon after leaves appear following summer, during the period of flower bud growth (winter), while flowering (summer) and as the fruit developed (summer). Due to the current severe drought conditions in Australia, the plants at both populations failed to produce flowers and thus fruit in 2006. Collection were therefore made at three stages, i) soon after leaves appeared, ii) the period of flower bud growth and iii) dormancy (summer). SEM has been used to determine the location, type and amount of mycorrhizal colonisation.

The SEM study has shown that the area of fungal colonisation in both species occurs in the roots as in Ramsay et al.1986, in particularly the mid to upper root sections, not in the growth tip. The colonisation primarily occurs in the cortical and velamen cells (Figure 1. B), as the fungi enter the orchid through the epidermis and form balls of hyphae known as peletons inside the cells (Figure 2. C).

\section{Fungal Isolations}

Under aseptic conditions, sectioned field material was sterilised for four minutes with $0.5 \% \mathrm{NaCl}$ were examined with $\times 40$ magnification using a black background in sterile water. The sections were then cut longitudinally into 5-6 slices. Using the back of a scalpel blade, the slices were rubbed to release the peletons and transferred (Rasmussen et al. 1990) to individual FIM medium (Clements \& Ellyard 1979) with a small amount of water, using a separate glass pipette for each section (Ramsay et al. 1986). Plates were then sealed and placed in a biological control cabinet. The plates were examined after one week for hyphal growth.

Fungal isolates from all plants were tested for their ability to germinate seed on oats media with differing sucrose levels ( 0 grams, 2 grams, 4 grams and 10 grams). One fungal isolate from $P$. diversiflorum isolated at leaf emergence germinated a low number of $p$. sp. validum seed. Fungi isolated from plants during flower budding have successfully germinated seed from both species' corresponding seed. Within two months of the seed germination trials the protocorms developed green leaves (Figure 1. C \& D, Figure 2. D).

\section{Fungal Morphology}

The morphology of the fungi is similar in both species. According to Warcup (1981), the fungi associated with Prasophyllum have been found to be basidiomycetes belonging to the genus Ceratobasidum, species cornigerum. Genetic sequencing of all fungal isolates from plants of $P$. sp. validum and $P$. diversiflorum identified at least two symbionts, Rhizoctonia sp. and Ceratobasidium cornigerum along with other soil fungi. Further research will use molecular techniques to determine further fungal identity.

ACKNOWLEDGMENTS. We would like to acknowledge the generous funding of the Australian Orchid Foundation, the Australian Biological Resources Study, The School of Botany and the Holsworth Wildlife Research Endowment. We also acknowledge the Department of Sustainability and Environment. 


\section{Literature Cited}

Batty, A.L., M.C. Brundrett, K.D. Dixon \& K. Sivasithamparam. 2006. New Methods to Improve Symbiotic Propagation of Temperate Terrestrial Orchid Seedlings from Axenic Culture Soil. Austral. J. Bot. 53: 367-374.

Clements, M. \& R. Ellyard. 1979. The symbiotic germination of Australian terrestrial orchids. Amer. Orchid Soc. Bull. 48: 810-815.

Jones, D.L. 1998. Contributions to Tasmanian Orchidaceae- 6: a Taxonomic Review of Prasophyllum R.Br. in Tasmania. Austral. Orchid Res. 3: 94-134.

Ramsay, M.M., Dixon, K.W. \& Siasithamparam, k. (1986). Patterns of infection and endophytes associated with Western Australian orchids, Lindleyana 1: 203-214.
Rasmussen, H.N., T.F. Andersen \& B. Johansen. 1990. Temperature sensitivity of in vitro germination and seedling development of Dactylorhiza majalise (Orchidaceae) with and without a mycorrhizal fungus. P1. Cell Environm. 13: 171-177.

Rasmussen, H. 1986. Cell differentiation and mycorrhizal infection in Dactylorhiza majalis (Rchb. F.) Hunt \& Summerh. (Orchidaceae) during germination in vitro. New Phytologist, 116: 137-147.

Warcup, J.H. 1981. The Mycorrhizal Relationships of Australian Orchids. New Phytologist 87: 371-381.

Backhouse, G.N. \& J. Jeanes. 1995. Orchids of Victoria.

Bishop, T. 1996. Field guide to the Orchids of New South Wales and Victoria, $2^{\text {nd }}$ edn. University of New South Wales, Sydney. 
LANKESTERIANA 